\title{
Investigación
}

\section{Fundamentos constitucionales del sistema tributario y eficientismo fiscal}

\author{
Constitutional foundations of the tax system \\ and fiscal efficiency
}

Diego Fernando Tarapués Sandino

Óscar Andrés Rodríguez Sandino²

Recepción: 29/01/2021 • Aprobación: 25/03/2021 • Publicación: 17/11/2021

Para citar este artículo

Tarapués Sandino, D. F., \& Rodríguez Sandino, O. A. (2021). Fundamentos constitucionales del sistema tributario y eficientismo fiscal. Dos mil tres mil, 23, e317. https://doi.org/10.35707/dostresmil/23317

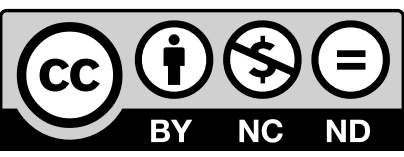

${ }^{1}$ Investigador Senior de MinCiencias adscripto al Grupo GICPODERI. Profesor Titular escalafonado de la Universidad Santiago de Cali, Cali, Colombia. Investigador del CEDPAL, Alemania. orCid: 0000-0003-0048-655X. Correo electrónico: dtarapues@usc.edu.co ${ }^{2}$ Estudiante de la Maestría en Dirección Empresarial de la Universidad Santiago de Cali, Cali, Colombia. ORCid: 0000-0001-65919235. Correo electrónico: oscararodriguezs76@hotmail.com 
Resumen. El presente artículo analiza el marco constitucional del sistema tributario. Se hace énfasis en los desarrollos jurisprudenciales de la Corte Constitucional sobre la tributación y se plantea una crítica a la política fiscal y tributaria que se centra en medidas eficientistas. El artículo parte de las repercusiones que tiene el Estado social de derecho en la concreción del principio de solidaridad y en el deber de contribución fiscal. Luego se revisan los alcances de cada principio constitucional del sistema tributario. Finalmente, se hace una crítica sobre lo que aquí se denomina eficientismo fiscal, que consiste en centrar la labor impositiva y de recaudo en medidas que sobreponen la eficiencia por encima de los demás principios que deben orientar el sistema tributario.

Abstract. This article analyzes the constitutional framework of the tax system. Emphasis is placed on jurisprudential developments of the Constitutional Court regarding taxation and a criticism of fiscal and tax policy is raised that focuses on efficient measures. The article starts from the repercussions that the Social Rule of Law has on the realization of the principle of solidarity and on the duty of fiscal contribution. Then the scope of each constitutional principle of the tax system is reviewed. Finally, a criticism is made of what is here called fiscal efficiency, which consists of focusing tax and collection work on measures that superimpose efficiency above other principles that should guide the tax system.

\section{Palabras claves}

Principios del sistema tributario, eficientismo fiscal, Estado social de derecho, constitución.

Key words

Principles of the tax system, fiscal efficiency, Social Rule of Law, constitution. 


\section{Introducción}

La materialización del proceso constituyente de 1991 contribuyó significativamente a fijar un modelo constitucional que sujeta la política fiscal y tributaria a presupuestos emanados del conjunto de valores y postulados que caracterizan al Estado social de derecho. La constitucionalización del derecho tributario, a partir de la Carta Política de 1991, ha sido un gran logro, al menos desde el punto de vista formal y jurídico. Sin embargo, la ausencia de desarrollo normativo específico que decante los alcances jurídicos de los diferentes principios constitucionales del sistema tributario ha conducido a que la jurisprudencia emanada de la Corte Constitucional llene estos espacios.

En efecto, ante la mera enunciación normativa de estas categorías jurídicas, la Corte Constitucional, como guardiana de la norma fundamental, ha decantado los alcances de los principales elementos que conforman el sistema tributario colombiano en el marco de su labor hermenéutica (Romero, Bernal \& Soto, 2012). Así, la jurisprudencia ha sido la encargada de darle contenido tanto al concepto de tributo, como al de los principios de la tributación nacional.

En ese orden de ideas, la Sentencia C-228 de 1993 constituye la decisión fundacional en la materia, la cual señala por primera vez, aunque de forma muy genérica, que el tributo es "un aporte razonable que debe hacer toda persona, social por naturaleza, fundamentado en el consenso de la voluntad general por medio de la ley" (p. 7). Hoy en día, con base en una acepción más completa e integral, la Corte comprende bajo el concepto de tributos:

Aquellas prestaciones que se establecen por el Estado en virtud de la ley, en ejercicio de su poder de imperio, destinados a contribuir con el financiamiento de sus gastos e inversiones en desarrollo de los conceptos de justicia, solidaridad y equidad. (Corte Constitucional, Sentencia C-704, 2010).

De igual forma, la Corte ha desarrollado y entrelazado los distintos principios constitucionales en este ámbito, precisando que se aplican al sistema en su conjunto y que estos orientan cualquier actividad de regulación fiscal y tributaria. Efectivamente, la Constitución de 1991, en su componente económico y de hacienda pública, ha fijado las bases generales que determinan el sistema impositivo en Colombia. En especial, el artículo 363 constitucional señala de manera precisa que este sistema "se funda en los principios de equidad, eficiencia y progresividad", resaltando que, en todo caso, "las leyes tributarias no se aplicarán con retroactividad".

Aunque esta disposición es clara en señalar que los mencionados principios fundamentan la estructura de la normatividad tributaria, lo cierto es que no constituyen enclaves desvinculados del conjunto sistemático de disposiciones que encierra la Constitución. Desde la parte dogmática del ordenamiento constitucional se establecen algunos presupuestos transversales que orientan los alcances jurídicos de los mencionados principios del derecho tributario, los cuales deben ser considerados tanto en la configuración legislativa de los impuestos, como también en la interpretación y aplicación de las normas que los fijan. Más aún en el contexto colombiano 
en el que, desde la expedición de la actual Carta Política, se decidió constitucionalizar al derecho tributario.

A partir de esta reflexión general, el presente artículo se propone analizar algunos aspectos del marco constitucional del sistema tributario, detallando en los desarrollos jurisprudenciales y doctrinarios que han esclarecido los alcances jurídicos de las diferentes disposiciones, que desde la normativa superior delimitan y dan sentido tanto a la labor de la legislación tributaria, como también al diseño de la política fiscal. Para ello, se abordarán las repercusiones que tiene el Estado social de derecho en el perfilamiento del principio de solidaridad y en la concreción del deber de contribución fiscal. Luego se revisarán los alcances de cada principio de la tributación que han sido constitucionalizados en la Carta Política de 1991.

Por último, se plantea una reflexión crítica sobre el eficientismo fiscal y tributario, entendido como una política en este ámbito dirigida a centrar la labor impositiva y de recaudo en disposiciones normativas que sobreponen la eficiencia por encima de los principios de progresividad y equidad, que igualmente deben orientar el sistema tributario. En ese sentido, se hará énfasis en la tendencia de ampliar los impuestos indirectos, en tanto se brindan beneficios y minoraciones a personas jurídicas, a partir de intervenciones económicas dirigidas a fomentar el crecimiento de ciertos sectores y a generar empleo formal.

\section{Del principio de solidaridad al deber de contribución en el Estado social de derecho}

El Estado administra y gestiona tanto los ingresos como los gastos presupuestales, siendo este el recaudador natural de los recursos fiscales y el inversor esencial de los dineros públicos (Restrepo, 2012). El uso de políticas tributarias para corregir o subsanar ciertos déficits fiscales constituye una forma de intervención económica por parte del Estado (Forero, 2019). Dentro de la labor fiscal de recaudo de ingresos para la financiación del funcionamiento de la organización estatal y para llevar a cabo las políticas públicas que impactan en la satisfacción de las necesidades básicas, así como en el mejoramiento de la calidad de vida de los asociados, se evidencia la existencia de un conjunto de medidas e instrumentos de política fiscal orientados por los lineamientos que, en la materia, fija la norma fundamental.

Ante todo, el principal presupuesto constitucional que se debe considerar para la imposición de cualquier carga de naturaleza fiscal está dado por el modelo de Estado asumido por nuestra nación, es decir, por la concepción axiológica del Estado social de derecho, como estructura organizacional que da sentido a los demás principios, deberes y disposiciones que regulan este y otros asuntos. Sobre el particular, la Corte Constitucional ha sostenido que:

El Estado Social de Derecho ya no se limita solamente a asegurar la vida, la propiedad y la libertad mediante la protección contra el fraude, el hurto, el incumplimiento contractual o los daños ocasionados por terceros, funciones típicas del Estado gendarme. Sus fines tienen mayor alcance e incluyen, entre otros, promover la prosperidad general; garantizar la efectividad de los principios, 
derechos y deberes consagrados en la Constitución; facilitar la participación de todos en las decisiones que los afectan y en la vida económica, política, administrativa y cultural de la Nación; y asegurar la vigencia de un orden justo (art. 2. ${ }^{\circ}$ de la C.P.). Para ello, el Estado cuenta con facultades amplias de intervención en la economía, las cuales han de estar orientadas a lograr los fines generales del Estado y los fines especiales de la intervención económica enunciados principalmente en el artículo 334 de la Constitución. Entre estos fines especiales se destacan el de 'asegurar que todas las personas, en particular las de menores ingresos, tengan acceso efectivo a los bienes y servicios básicos' (art. 334 de la C.P., inc. 2. ${ }^{\circ}$ ). (Corte Constitucional, Sentencia C-776 de 2003).

De cara a este modelo de organización política, jurídica y económica es que se desprende el entramado dogmático y orgánico, en el que se articula la materialización de los derechos fundamentales con la creación y funcionamiento de un sinnúmero de órganos, instituciones y dependencias creadas para hacer efectivo lo que nuestra carta de derechos contempla. En otros términos, sin recursos económicos no es posible velar por la efectiva realización y garantía de las libertades fundamentales y de los derechos civiles, políticos, económicos, sociales, culturales y colectivos. Así, en el desarrollo de su quehacer, "el Estado realiza gastos, por lo que debe procurar recursos económicos para cubrirlos" (Cadavid, 2014, p. 222), siendo los tributos uno de los principales ingresos del andamiaje estatal.

Desde el mismo articulado constitucional se plantea no solo la triada de los principios tributarios (equidad, eficiencia y progresividad), sino también la lógica contributiva de las personas tanto naturales como jurídicas, a partir de deberes constitucionales derivados de los mismos fines que persigue el Estado social de derecho y en virtud de las relaciones de solidaridad que se imponen en el entramado social. En ese sentido, la Corte Constitucional ha sido enfática en señalar que:

[L]a efectiva realización del principio de Estado Social de Derecho presupone la obligación del pago de tributos por parte de los particulares. Tal conclusión se desprende del principio de solidaridad (artículo 1 C.P.) y del deber de contribuir al financiamiento de los gastos e inversiones del Estado dentro de conceptos de justicia y equidad (artículo 95 inciso 3 numeral 9 c.P.). Es precisamente en el contexto de toma de decisiones macroeconómicas y sociales que los distintos sectores de la población, en virtud del principio de solidaridad, asumen cargas públicas razonables para permitir que sectores excluidos puedan progresivamente ser incorporados al goce de los beneficios del progreso, lo cual solo se puede lograr mediante la conciencia creciente de la necesidad de cooperar y actuar mancomunadamente para mejorar la calidad de vida de todos los colombianos y superar gradualmente las desigualdades presentes. (Corte Constitucional, Sentencias C-1064, 2001).

En ese orden de ideas, es posible sostener que la solidaridad como principio y categoría constitucional ubicua, junto con el deber fundamental de toda persona de contribuir al fisco, representan los presupuestos esenciales del régimen jurídico nacional en materia tributaria. Estos, a su vez, se derivan de un sistema de financiación e intervención social fomentado por el modelo axiológico del Estado social de derecho que ha adoptado el constituyente de 1991. 
Por esta razón, resulta necesario detallar en su anclaje constitucional para comprender cabalmente el sentido del sistema impositivo en Colombia.

\subsection{El principio de solidaridad y sus implicaciones en el ámbito fiscal y tributario}

En primer lugar, se debe resaltar que la solidaridad encarna un elemento normativo de gran valor dentro de la estructura fijada por la Asamblea Nacional Constituyente, comprendiendo diversas acepciones que van desde ser un principio transversal en la normativa fundamental, hasta configurar un deber de todo ciudadano en la cotidianidad. Así, desde el mismo preámbulo se pregona que la expedición de la nueva Constitución tiene entre sus finalidades la de "fortalecer la unidad de la nación” y "asegurar a sus integrantes la vida, la convivencia [...] dentro de un marco jurídico, democrático y participativo que garantice un orden político, económico y social justo".

Dentro del conjunto de los principios fundamentales, el artículo $1 .^{\circ}$ de la Constitución sostiene que "Colombia es un Estado social de derecho" que se funda "en el respeto de la dignidad humana, en el trabajo y la solidaridad de las personas que la integran y en la prevalencia del interés general"; mientras que el artículo 2. ${ }^{\circ}$ señala que un fin esencial del Estado es "promover la prosperidad general" y "asegurar la convivencia pacífica y la vigencia de un orden justo". Sin lugar a duda, estos principios y finalidades irradian en diversas disposiciones a lo largo del texto constitucional.

En ese sentido, la normativa fundamental establece, entre los artículos 44 al 47, a las relaciones solidarias como un principio rector de las funciones colectivas encaminadas a la protección de grupos con mayor vulnerabilidad, entre los cuales se destacan los niños, los adolescentes, las personas de la tercera edad y las personas con discapacidad; en tanto que los artículos 48, 49 y 367 la incluyen dentro de la fijación del modelo de seguridad social, salud, saneamiento ambiental y de prestación de servicios públicos domiciliarios (Parra, 2012, p. 61). Además, el numeral 2. ${ }^{\circ}$ del artículo 95 de la Constitución establece que es deber de toda persona "[o]brar conforme al principio de solidaridad social, respondiendo con acciones humanitarias ante situaciones que pongan en peligro la vida o la salud de las personas".

Finalmente, la solidaridad se predica respecto de los poderes de ordenamiento presupuestal según dan cuenta los artículos constitucionales 350, 355, 359 y 366; de igual forma, se considera que constituye "una de las justificaciones del ejercicio del poder impositivo" (Parra, 2012, p. 61), que se regenta por la progresividad y equidad tributarias de conformidad con el artículo 363 de la Constitución (Corte Constitucional, Sentencia C-776 de 2003).

\subsection{El deber de contribución al gasto público como base de la carga tributaria}

Ahora bien, de la solidaridad emana el deber ciudadano de contribuir con el pago de impuestos y tasas que se fijen para financiar el funcionamiento de la organización estatal y la realización de sus diferentes cometidos. Por consiguiente, se debe precisar que la obligación tributaria, a través 
de la cual se vincula al Estado con las personas consideradas como contribuyentes, surge como un deber de toda persona (nacional o extranjera) sujeta al cumplimiento del ordenamiento jurídico colombiano. En esta dirección, el artículo $4 .^{\circ}$ de la Constitución sostiene el "deber de los nacionales y de los extranjeros en Colombia [de] acatar la Constitución y las leyes, y respetar y obedecer a las autoridades", mientras el artículo $6 .^{\circ}$ precisa que los particulares (nacionales o extranjeros) "son responsables ante las autoridades por infringir la Constitución y las leyes".

En estricto sentido, el numeral 9. del artículo 95 del texto constitucional contiene el deber de toda persona de "[c]ontribuir al financiamiento de los gastos e inversiones del Estado dentro de conceptos de justicia y equidad". Este deber ciudadano y empresarial de contribuir al fisco representa el fundamento constitucional de la carga tributaria. A partir de esta sujeción, el Estado puede exigir el cumplimiento de este tipo de obligaciones, tanto aquellas de dar, es decir, pagar impuestos, tasas y contribuciones especiales, como también las de hacer, esto es, registrarse en los sistemas de información y presentar declaraciones de impuestos. En este contexto, se les da prelación jurídica a los créditos fiscales frente a otro tipo de acreencias y se han estructurado procesos de cobro coactivo por parte de la misma administración para facilitar la exigencia del pago de dichas obligaciones (Estatuto Tributario, arts. 823 y ss.).

De igual forma, la infracción a este deber sustenta la concreción de un bien jurídico supraindividual en el ámbito del derecho penal (Ferré, 2014, p. 7), en el que se enmarcan los delitos relacionados con la omisión de activos, la defraudación y la promoción de estructuras de evasión tributaria. El hecho de llevar hasta el ámbito de las normas penales el incumplimiento de las obligaciones tributarias permite evidenciar la importancia que le da el Estado a los recursos que capta a partir de las imposiciones fiscales asignadas a los contribuyentes al gasto público. De esta forma, la legislación penal, contentiva de las normas de ultima ratio, contempla delitos tributarios como la "omisión de activos o inclusión de pasivos inexistentes", la "defraudación o evasión tributaria" y la "omisión del agente retenedor o recaudador" (Código Penal, arts. 434a, $434 \mathrm{~b}$ y 403$)$.

Aunque la solidaridad y el deber de contribuir se pregonan indistintamente de todas las personas, la misma estructura axiológica del Estado social de derecho enfatiza en la equidad, eficiencia y progresividad como ejes que dinamizan las imposiciones fiscales y los alcances de las contribuciones en materia tributaria; esto constituye un imperativo constitucional que debe ser valorado por las autoridades involucradas no solo en configurar legislativamente los tributos, sino también en examinarlos y ejecutarlos.

Así lo público sea asunto de todos y sin diferenciación alguna, cada persona tiene:

El deber de contribuir a la acción común con un sacrificio personal, en la medida de sus posibilidades, ello no otorga la liberalidad absoluta del legislador en la configuración del tributo, sino que este siempre deberá respetar el criterio de justicia a fin de diseñar un régimen tributario general, solidario y progresivo. (Bolaños, 2017, p. 67). 
Estos presupuestos, que orientan la labor desplegada por el legislador tributario al definir las normas en las que se expresa la política fiscal del Estado, encuentran un amplio desarrollo jurisprudencial que debe ser valorado con la finalidad de revisar el modelo de justicia tributaria pregonado desde el ordenamiento constitucional.

\section{Los principios fundamentales del sistema tributario}

Aparte del principio de solidaridad y del deber de contribución, la Constitución prevé en el artículo 363 los principios de equidad, eficiencia y progresividad, así como la prohibición de su imposición retroactiva junto con la obligación de que se emitan bajo estricta legalidad. Estos principios, más que regir sobre cada tributo en particular, han sido interpretados y aplicados de manera conjunta frente al sistema tributario. Al respecto, la Corte Constitucional ha señalado que estos "son predicables del sistema tributario en su conjunto y no de un impuesto en particular", es decir, "constituyen los parámetros para determinar la legitimidad del sistema tributario" (Corte Constitucional, Sentencia C-397, 2011).

Asimismo, son disposiciones dadas por el constituyente para hacer coherentes las relaciones entre los contribuyentes y el Estado (Forero, 2019). Al no existir definición constitucional ni legal de estos principios que cimientan la tributación colombiana, la Corte Constitucional se ha encargado de darle alcance a cada uno de ellos en su labor de garantizar jurisdiccionalmente la supremacía e integridad de la norma fundamental.

\subsection{El principio de equidad tributaria}

La jurisprudencia constitucional ha sostenido de forma reiterada que la equidad, en el marco del sistema tributario, representa "un criterio con base en el cual se pondera la distribución de las cargas y de los beneficios o la imposición de gravámenes entre los contribuyentes para evitar que haya cargas excesivas o beneficios exagerados" (Corte Constitucional, Sentencia C-776, 2003). Al respecto, se debe precisar que una carga es entendida como excesiva cuando no considera la capacidad económica que tienen las personas a la hora de tributar "en razón a la naturaleza y fines del impuesto en cuestión" (Corte Constitucional, Sentencia C-734, 2002).

La concepción del principio tributario de equidad no se desmarca de los presupuestos constitucionales dados a la igualdad desde el mismo preámbulo y, en especial, a partir del artículo 13, el cual positiviza internamente este derecho humano a través de sus diferentes expresiones dogmáticas, esto es: i) igualdad ante la ley; ii) prohibición de discriminación por cualquier razón; iii) promoción de igualdad real y efectiva; y iv) protección especial a personas en circunstancias de debilidad manifiesta. Además de fijar las bases de la igualdad legal y de la promoción de la igualdad material, fomentando incluso las acciones afirmativas y las políticas de reconocimiento como factores orientados a zanjar las brechas existentes, el entramado constitucional en la materia presupone la concreción del principio tributario de equidad en aras de equilibrar las cargas impositivas a todas las personas. 
En efecto, se ha precisado que la igualdad "es un principio universal de protección, que en el derecho tributario limita el ejercicio de la potestad legislativa del legislador", y que junto con "la equidad y la justicia tributaria son fundantes de la igualdad de trato e igualdad diferenciada justificada y es base de la idea de justicia tributaria" (Sentencia C-291 de 2015, Corte Constitucional citada por Bolaños, 2017, p. 69).

En ese sentido, la equidad implica que, de acuerdo con la valoración que realice el legislador tributario, se deben gravar:

Los bienes o servicios cuyos usuarios tienen capacidad de soportar el impuesto, o aquellos que corresponden a sectores de la economía que el Estado pretende estimular, mientras que se exonere del deber tributario a quienes, por sus condiciones económicas, pueden sufrir una carga insoportable y desproporcionada como consecuencia del pago de tal obligación legal. (Corte Constitucional, Sentencia C-776, 2003).

Justamente la valoración de los alcances jurídicos del principio de equidad tributaria ha dado lugar a que se diferencie en el ámbito de la progresividad entre los conceptos de equidad horizontal y equidad vertical, ya que "en el proceso de imposición de determinada carga tributaria se debe tener en cuenta de manera específica la situación en que se encuentran quienes están llamados a contribuir y su capacidad de pago" (Corte Constitucional, Sentencia C-261, 2002). En efecto, la imposición de cualquier carga tributaria debe ser proporcional a la capacidad de pago que tenga el contribuyente. Así, hay equidad horizontal siempre que las personas iguales paguen impuestos equivalentes a sus niveles de renta, mientras que la equidad vertical atiende a que las personas tributen de manera diferenciada partiendo de los distintos niveles de renta.

\subsection{El principio de eficiencia tributaria}

Ahora bien, respecto al principio de eficiencia, este ha sido concebido por el órgano de cierre de la jurisdicción constitucional a partir de la valoración racional de las variables costo/beneficio, tanto en el proceso de recaudo como en el espíritu mismo del régimen tributario. Por un lado, desde el punto de vista económico, la eficiencia se considera cuando se enfoca en obtener un mayor recaudo tributario con el menor costo operacional posible; por otro lado, desde lo social implica que la política fiscal y tributaria debe significar "el menor costo social para el cumplimiento del deber fiscal” (Bolaños, 2017, p. 71). Así pues, cuando se fijan medidas tributarias ineficientes se da lugar a "una injusta distribución de la carga fiscal" producto "del incumplimiento de la obligación por parte de algunos contribuyentes que conduce al soporte de gastos e inversión por parte de otros contribuyentes" (Bolaños, 2017, p. 71).

Efectivamente, la jurisprudencia en la materia valora la orientación que da este principio al legislador en el logro de que "la imposición acarree el menor costo social para el contribuyente en el cumplimiento de su deber fiscal (gastos para llevar a cabo el pago del tributo)" (Corte Constitucional, Sentencia C-419, 1995). Este principio se pregona tanto del diseño de 
los impuestos por parte del legislador, como también del proceso de recaudo adelantado por la administración (Corte Constitucional, Sentencia C-776, 2003).

En otros términos, el principio tributario de eficiencia implica que la labor de recaudo se lleve a cabo al menor coste posible y, a la vez, con la mayor facilidad posible. De tal forma, que "un sistema tributario eficiente asegura el efectivo control de la recaudación de los dineros públicos, donde la eficiencia se comporta como un recurso técnico orientado al mayor recaudo" (Bolaños, 2017, p. 72). En la práctica, este principio tiene diversas expresiones, por ejemplo:

En proporción de egresos necesarios para generar el ingreso, en tarifas impositivas moderadas sobre bases impositivas que obedezcan a la naturaleza misma de la imposición, en la determinación práctica del responsable del impuesto, en clasificaciones tributarias claras, exenciones con argumentación razonable y práctica, tratamientos diferenciados en atención a la equidad, entre otros. (Bolaños, 2017, p. 72).

En síntesis, el alto tribunal de lo constitucional ha sostenido que un impuesto resulta eficiente en su diseño, siempre y cuando genere pocas distorsiones económicas o en tanto el impuesto permita obtener la mayor cantidad de recursos al menor costo posible. Frente a la primera acepción de eficiencia "se toma en consideración el impacto general que produce una carga fiscal sobre el escenario económico"; por su parte, en la segunda, "se valoran exclusivamente los resultados de la carga fiscal en cuestión" (Corte Constitucional, Sentencia C-776, 2003). Así pues, la eficiencia en el recaudo se pasa a medir a través de la valoración sobre "qué tantos recursos logra recaudar la administración bajo las normas vigentes" (Corte Constitucional, Sentencia C-776, 2003).

\subsection{El principio de progresividad tributaria}

Con relación a la progresividad, la Corte ha vinculado este principio con la capacidad de pago de los contribuyentes desde una perspectiva vertical de equidad, es decir, atendiendo a la lógica según la cual entre mayor capacidad económica tiene una persona, mayores impuestos le corresponden. En este sentido, la jurisprudencia la establece como una manifestación concreta del principio de equidad (Corte Constitucional, Sentencia C-989, 2004). En efecto, la progresividad es una propiedad que se extrae de la equidad vertical, predicándose del conjunto que conforma la totalidad del sistema tributario y representando a su vez un parámetro que legitima al régimen tributario (Corte Constitucional, Sentencia C-397, 2011).

La correlación de los principios tributarios de equidad y progresividad se da:

En la distribución de las cargas y los beneficios tributarios, siendo la equidad un criterio más amplio de ponderación para determinar el efecto de una imposición sobre cada destinatario, en tanto que la progresividad consulta la modificación de la situación económica de un grupo de personas frente a otras. (Bolaños, 2017, p. 74). 
Por tal razón, se dice que la política tributaria debe atender a las diferencias económicas dadas en la sociedad (riqueza y rentas):

De modo que la obligación fiscal, como expresión de la solidaridad social, considere la capacidad contributiva de los sujetos y grupos que la componen, para desde allí determinar la carga fiscal que ha de asignar con el criterio jurídico de progresividad, y así contribuye efectivamente con una de las funciones de la imposición: la redistribución del ingreso nacional. (Bolaños, 2017, p. 74).

En ese orden de ideas, un sistema tributario es progresivo en la medida que repare en la distribución de las cargas impositivas entre los contribuyentes de cara a la capacidad que tiene cada persona. Así pues, constituye "un criterio de análisis de la proporción del aporte total de cada contribuyente en relación con su capacidad contributiva" (Corte Constitucional, Sentencia C-776, 2003). De cara a este criterio es posible clasificar en tres niveles el relacionamiento del régimen tributario con este principio: (i) si el sistema conserva las diferencias relativas entre los aportantes de mayor y menor capacidad contributiva se está ante un modelo neutro; (ii) si se reducen las cargas se considera un sistema progresivo; y, finalmente, (iii) si está dirigido a aumentar las cargas entonces se trata de un régimen regresivo (Corte Constitucional, Sentencia C-776, 2003).

Finalmente, la Corte Constitucional advierte de una dimensión más amplia de este principio estimando el destino y los efectos del gasto público que ha sido solventado a través del recaudo fiscal; de tal forma que la neutralidad, progresividad o regresividad del sistema tributario resultaría de cotejar las condiciones económicas de los diferentes niveles de la sociedad tras la ejecución del gasto público (Corte Constitucional, Sentencias C-776, 2003; C-637, 2000; C-597, 2000; C-335, 1994; C-333, 1993).

\subsection{El principio de legalidad e irretroactividad tributaria}

En cuanto al principio de legalidad, este parte de la determinación de disposiciones constitucionales que tienen la labor de configuración legislativa en el ámbito tributario. A partir de la máxima sin representación no hay tributación, heredada del movimiento constitucionalista liberal inglés, se pregonan una serie de presupuestos jurídicos en el ordenamiento constitucional que impactan en la elaboración y aplicación de los tributos en Colombia, estos son:

a) El Congreso no puede revestir pro tempore al Presidente de la República para que expida decretos extraordinarios sobre impuestos, b) En tiempos de paz, solamente el Congreso, las Asambleas departamentales y los Concejos municipales y distritales podrán imponer contribuciones fiscales y parafiscales, c) Solo la Ley, las ordenanzas y los acuerdos, en su caso, podrán determinar los sujetos activos y pasivos, los hechos y las bases gravables y las tarifas de los impuestos, pero estos dos últimos siempre con sujeción a una ley, d) Las normas tributarias no podrán iniciar su vigencia sino a partir del periodo que comience después de iniciar la vigencia de la respectiva ley, ordenanza o acuerdo, e) Muy excepcionalmente en un régimen presidencial como el nuestro, el Presidente puede 
decretar impuestos en los estados de excepción y en tal caso, tendrán la vigencia que limitadamente han establecido los artículos 212, 213 y 215 de la Constitución. (Hincapié, 2014, p. 48).

La legalidad tributaria hace parte fundamental del andamiaje que brinda seguridad jurídica y certeza al contribuyente acerca de sus deberes fiscales para con el Estado y sobre su patrimonio. La seguridad jurídica en el derecho tributario es clave no solo para contener cualquier actuación arbitraria de los gobernantes en la materia, sino también para garantizarles objetivamente a los contribuyentes tanto sus bienes como sus derechos y para brindarles la confianza que les permita "actuar, invertir y proyectarse desde una perspectiva subjetiva" (Hincapié, 2014, p. 48). En consideración de los anteriores presupuestos constitucionales, se predica que el principio de legalidad tributaria presenta las siguientes características:

a) Es expresión de representación popular y del principio democrático, b) materializa el principio de predeterminación del tributo, según el cual una lex previa y certa debe señalar los elementos de la obligación fiscal, c) brinda seguridad a los ciudadanos frente a sus obligaciones fiscales, d) responde a la necesidad de promover una política fiscal coherente e inspirada en el principio de unidad económica, especialmente cuando existen competencias concurrentes donde confluye la voluntad del Congreso y la de las asambleas departamentales o de los concejos municipales, e) no se predica únicamente de los impuestos, sino que es exigible también frente a cualquier tributo o contribución (en sentido amplio), f) de conformidad con el mandato constitucional contenido en el artículo 338, no solo el legislador, sino también las asambleas y los concejos están facultados para fijar los elementos constitutivos del tributo, g) la ley, las ordenanzas y los acuerdos, sin resignar sus atribuciones constitucionales, pueden autorizar a las autoridades de los distintos niveles territoriales, dentro de los límites señalados en ellas, para fijar las tarifas de las tasas y contribuciones que cobren a los contribuyentes. (Corte Constitucional, Sentencia C-891, 2012).

Por último, se debe advertir que del mismo principio de legalidad tributaria emana "la prohibición de los efectos retroactivos de la ley tributaria" (Hincapié, 2014, p. 48). Efectivamente, el artículo 363 de la Constitución establece de manera clara y contundente que las "leyes tributarias no se aplicarán con retroactividad". Esta proscripción imperativa fijada por el constituyente de 1991 apunta a superar "un historial infortunado de aplicación retroactiva de la ley tributaria en razón a que la Constitución de 1886 no disponía de manera específica sobre el particular" (Upegui, 2011, p. 156).

En consecuencia, el principio de irretroactividad que rige para la legislación y políticas en este ámbito prevé que "las normas tributarias no pueden regular hechos tributarios sino a partir de su promulgación" (Forero, 2019, p. 19); lo cual significa, en otras palabras, que no es posible que tengan "vigencia sobre períodos anteriores a la misma Ley" (Avellaneda, 1997, p. 111). En conclusión, es posible sostener que la esencia de este principio tributario radica en brindar seguridad jurídica de que el poder impositivo estatal no modificará "la tributación con efectos retroactivos, con perjuicio de los contribuyentes de buena fe" (Romero, Grass \& García, 2013, p. 74). 


\section{El eficientismo fiscal como núcleo esencial de las reformas tributarias}

En el plano nacional, el ordenamiento jurídico cuenta con una codificación que agrupa las principales directrices regulatorias de las obligaciones tributarias y del relacionamiento del Estado con los contribuyentes, desarrollando jurídicamente el grueso de las decisiones asumidas por el Estado en el diseño de su política fiscal. Si bien esta normativa denominada como "Estatuto Tributario de los Impuestos Administrados por la Dirección General de Impuestos Nacionales" se expidió de manera previa a la promulgación de la Constitución Política de 1991 (Decreto 624 de 1989 en virtud de las leyes 75 de 1986 y 43 de 1987), la misma ha sido objeto de múltiples reformas legales y de diferentes controles de constitucionalidad, a la luz de los procedimientos y disposiciones sustanciales que fija el modelo constitucional diseñado por la Asamblea Nacional Constituyente.

El Estatuto Tributario constituye la normativa vertebral del derecho tributario colombiano, al cual cada gobierno suele introducirle reformas adelantadas en el Congreso de la República, con el propósito de solventar las variaciones en el gasto público. Dentro de esa dinámica reformatoria es posible evidenciar una tendencia dirigida a ampliar gradual y sistemáticamente los impuestos indirectos, en tanto se disminuye la carga directa a ciertas personas jurídicas encargadas de dinamizar la economía y la generación de empleo en ciertos sectores (Farné, 2020).

En este contexto, se considera al gasto público y al impuesto como las instituciones (jurídicas) más representativas tanto de la política tributaria como de la fiscal; entendida la primera de estas políticas como el "instrumento económico que utiliza el Estado para el estudio de recaudo de tributos" (Forero, 2019, p. 18), mientras que la segunda encarna el "instrumento económico que permite estimular o desestimular la economía (o sectores económicos) a través de la imposición y recaudo de impuestos" (Forero, 2019, p. 18).

Como es de conocimiento general, los Estados en el marco de su política fiscal y tributaria suelen "fijar impuestos directos a los ciudadanos por sus propiedades y rentas junto con imposición amplia de impuestos indirectos provenientes del consumo, importación o exportación de bienes" (Forero, 2019, p. 17). Todas estas contribuciones adquieren una doble función (Barquero, 2002, citado por Bolaños, 2017), por una parte, juegan un rol financiero "en cuanto permite al Estado abastecerse de los ingresos necesarios para solventar los gastos e inversión" (Bolaños, 2017, p. 60), pero, por otra parte, desempeñan un rol redistributivo "en la medida en que sustrae recursos de los ciudadanos que sean objetiva y subjetivamente capaces de dar" (Bolaños, 2017, p. 60).

A la luz de la jurisprudencia constitucional, el régimen tributario "tiene que reparar en las diferencias de renta y riqueza existentes en la sociedad" (Corte Constitucional, Sentencias C-711, 2001; C-1107, 2001). Así, la función redistributiva de los impuestos tendría que manifestarse más en la imposición de los tributos directos que en los indirectos (Plazas, 2005; Bolaños, 2017). Sin embargo, como se detallará a continuación, en la realidad de la política fiscal 
y tributaria existe una tendencia que pareciera contrariar los propósitos deontológicos y axiológicos del marco constitucional del sistema tributario fijado desde el proceso constituyente de 1991.

\subsection{La ampliación gradual y sistemática de impuestos indirectos}

El aumento gradual de los impuestos indirectos ha sido una constante de las últimas reformas tributarias. Este tipo de tributos suelen imponerse a todos los colombianos de manera indistinta, sin atender a las condiciones y circunstancias en que se encuentren las personas, es decir, sin consideración alguna frente a cualquier factor de inequidad. El impuesto sobre las ventas y el gravamen a los movimientos financieros son los principales impuestos indirectos del orden nacional que han sido empleados para tal fin. Mientras el primero constituye un gravamen que recae sobre el consumo, siendo de carácter real, de causación instantánea y de régimen general (Buitrago \& Uribe, 2017), el segundo se extrae de las transacciones financieras que llevan a cabo las personas que acuden a la banca.

Pese a ser los menos solidarios y progresivos de los tributos, estos impuestos indirectos suelen ser el centro de variadas reformas en la materia que amplían los gravámenes, en razón a que se recaudan de manera eficiente y se facilita mucho su control. Lo anterior debido a que los primeros se hacen sobre cualquier producto dentro de la cadena de suministro, siempre que se genere algún tipo de valor agregado, en tanto que los segundos se identifican fácilmente a través de los registros bancarios que dejan los usuarios al mover cualquier suma de dinero en el sistema financiero.

El impuesto indirecto a los movimientos financieros surgió a finales de 1998 con el Decreto 2331 , concibiendo inicialmente un gravamen de 2 pesos por cada $\$ 1000$ movidos en transacciones, esto a efectos de atender la crisis bancaria que para la época tenía el país. Sin embargo, esta medida que debía desaparecer al año siguiente, se prolongó en el marco de la emergencia económica decretada tras el terremoto que sufrió el Eje Cafetero, reorientándose con ello el destino de los dineros captados. Al año siguiente se institucionalizó como un gravamen permanente y luego de haberse incrementado a 3 pesos de contribución por cada $\$ 1000$, quedó definido hasta el día de hoy con una tarifa de 4 x 1000.

Por su parte, el IVA aparece con el Decreto 3328 de 1963, pero con el pasar de los años se ha ido forjando una política fiscal enfocada en aumentar el recaudo a través de la ampliación tanto de productos, como del porcentaje al valor agregado a los bienes y servicios sobre los cuales se aplica este tributo. Tal como lo ha recapitulado la misma Corte Constitucional, este impuesto indirecto sobre las ventas:

Comenzó como un gravamen de una sola etapa aplicable sobre bienes elaborados de consumo final, que luego adquirió el diseño de un impuesto al valor agregado aplicable en las distintas etapas del proceso productivo sobre una base de gran amplitud, la cual abarca tanto bienes como servicios. (Corte Constitucional, Sentencia C-776, 2003). 
Además, la Corte advierte que las "tarifas — tanto la general como las diferenciales - también han experimentado una clara tendencia hacia el incremento" (Corte Constitucional, Sentencia C-776, 2003).

La Corte resalta que para algunos los impuestos indirectos como el IVA son tributos que pueden "conducir a que los sectores de menores ingresos se vean gravados con cargas exageradas en relación con su capacidad contributiva" (Corte Constitucional, Sentencia C-776, 2003); igualmente, señala que para otros es de carácter neutral, mientras que una última postura señala que aquellos que más tienen son quienes más consumen y, por lo tanto, más pagan, razón por la cual es posible plantear que es un tributo con elementos de progresividad, "máxime si el producido del mismo se invierte en beneficio de las personas de bajos ingresos, con lo cual este puede llegar a tener un efecto progresivo" (Corte Constitucional, Sentencia C-776, 2003).

Pese a que varias demandas han insistido en que la constitucionalización del derecho tributario contempla los principios de equidad y progresividad que eclipsan la concentración de la política fiscal y tributaria en el principio de eficiencia, la Corte Constitucional ha sido enfática en señalar que:

Algunos tributos - particularmente los indirectos-, por la mencionada conformación técnica y la necesidad de su administración eficiente, no son susceptibles de ser creados y recaudados atendiendo el criterio de la progresividad, sin que por ello dejen de tener fundamento constitucional y figurar entre las fuentes de ingresos fiscales. (Corte Constitucional, Sentencia C-364, 1993).

En otros términos, aunque "un impuesto en particular no cumpla con un principio, si el sistema tributario lo hace no se considera como inconstitucional" (Buitrago \& Uribe, 2017 p. 94). Este ha sido un planteamiento recurrente de la Corte Constitucional al examinar diferentes normas que han variado el IVA y han sido demandas de cara a los principios de equidad y progresividad. En este orden de ideas, la Corte ha desarrollado y sostenido una línea jurisprudencial, según la cual:

Como guardiana de la estricta sujeción del poder tributario a los mandatos constitucionales debe asegurarse que el sistema tributario, en su conjunto y en las leyes que lo integran, se informe en los principios de justicia y equidad, los cuales se concretan en las reglas y fórmulas de reparto de la carga tributaria y en la adecuada distribución del gasto público. (Corte Constitucional, Sentencia C-183, 1998).

La Corte ha señalado que las leyes sobre el IVA no son examinadas a la luz del principio constitucional de progresividad, ya que se trata de un impuesto indirecto sin fines progresivos. Por consiguiente, este impuesto no es objeto de un análisis concreto de valoración progresiva, sino que la progresividad siempre se examina de manera conjunta dentro del sistema tributario (Corte Constitucional, Sentencia C-776, 2003; C-597, 2000). En ese sentido, la jurisprudencia constitucional ha señalado que el IVA no vulnera la Constitución (Corte Constitucional, 
Sentencia C-333, 1993; C-597, 2000; C-094, 1993; C-556, 1993; C-597, 2000) y ha sustentado esta tesis en cuatro argumentos, al sostener:

(i) que la adquisición de un bien o servicio gravado indica que quien lo adquiere, tiene la capacidad de contribuir con el respectivo gravamen; (ii) que quien más consume, más aporta; (iii) que las personas gozan de libertad para adquirir o no adquirir bienes o servicios gravados; y (iv) que el significado del IVA para la progresividad del sistema tributario se concreta no solo en cuanto al aporte que se paga sino también en cuanto a la distribución de los beneficios que se obtienen en razón del gasto público financiado por el pago de dicho impuesto. (Corte Constitucional, Sentencia C-776, 2003).

Sin embargo, la misma Corte ha defendido que los principios constitucionales de equidad y progresividad, atendiendo al principio de Estado social de derecho, pueden imponer ciertos límites a la libertad de configuración del legislador frente al impuesto indirecto del IVA, cuando se valora el mínimo vital en la capacidad contributiva de las personas. Esta valoración emana del modelo axiológico de justicia tributaria que fija la Carta Política y ha permitido, aunque de manera muy reducida, la exoneración o reducción de la tarifa en bienes esenciales de primera necesidad, es decir, en algunos de los que conforman la canasta básica familiar. En esta línea, la Corte ha precisado que:

La capacidad contributiva es la posibilidad económica que tiene una persona de tributar, o sea, la idoneidad subjetiva, no teórica sino real, en cuanto depende de la fuerza económica del sujeto, para ser llamado a cumplir con el deber de pagar tributos. Entonces, las personas que apenas disponen de lo necesario para subsistir son las que tienen menor capacidad contributiva, o, inclusive, las que pueden carecer de capacidad económica de tributar. Llamar a quienes carecen de capacidad contributiva a soportar estas cargas públicas de orden impositivo que las afecta de manera ineludible y manifiesta en su subsistencia, resulta contrario a la justicia tributaria. La capacidad económica o contributiva, fundada, por ejemplo, en el ingreso, en la riqueza, o en una actividad productiva, no puede ser equiparada a la realización de una actividad social básica e ineludible, como adquirir un bien o servicio indispensable para sobrevivir. En ese sentido, la capacidad contributiva no es automáticamente equiparable a la capacidad adquisitiva. (Corte Constitucional, Sentencia C-776, 2003).

En ese orden de ideas, se debe resaltar que, de acuerdo con lo señalado por la Corte, aunque el legislador disponga de un elevado margen de configuración de la política tributaria de conformidad con el artículo 338 constitucional, esta disposición no le brinda una atribución exenta de límites. Por tal razón, el máximo intérprete de la Constitución sostiene que:

Cuando se extiende la base del Iva para gravar bienes y servicios, que antes habían sido excluidos para promover la igualdad real y efectiva (art. 13 de la C.P.) en un Estado Social de Derecho (art. $1 .^{\circ}$ de la C.P.), el legislador tributario vulnera los principios de progresividad y equidad que rigen el sistema tributario (art. 363 de la C.P. y art. 95-9 de la C.P.), interpretados en consonancia con el derecho fundamental al mínimo vital (arts. 1. ${ }^{\circ}$ y 13 de la C.P. en concordancia con el artículo 334 C.P.), si (i) de manera indiscriminada, sin el mínimo de deliberación pública en el seno del Congreso exigido por el respeto al principio de no tributación sin representación, se modifica un sistema 
tributario, (ii) con graves falencias tanto en el lado de los ingresos provenientes de tributos con diseño progresivo como (iii) en el lado del gasto encaminado a cumplir fines redistributivos, (iv) mediante la ampliación de la base del IVA a todos los bienes y servicios de primera necesidad (v) de los cuales depende ineludiblemente el goce efectivo del derecho al mínimo vital de un amplio sector de la población del país, dadas las insuficiencias de la red de protección social. (Corte Constitucional, Sentencia C-776, 2003).

No obstante, cada vez se han ido gravando más bienes hasta llegar actualmente al $60 \%$ de los productos de la canasta básica familiar con tarifas que oscilan entre el $5 \%$ y el $19 \%$ de IVA. Para esta finalidad, tanto los argumentos de conveniencia del legislador y del gobierno, como las interpretaciones y elucubraciones jurídicas desplegadas en su valoración por los jueces, han conducido a que se considere que algunos de los productos de la canasta familiar son sustituibles o son de menor importancia nutricional en el contexto nacional (Corte Constitucional, Sentencia C-776, 2003).

\subsection{La disminución constante de impuestos directos a ciertos sectores económicos}

En contraste con la práctica fiscal y tributaria de las diferentes administraciones que proponen la ampliación de los impuestos indirectos para recaudar mayores ingresos, las reformas tributarias de las últimas décadas suelen ser instrumentos de política fiscal dirigidas a incentivar ciertos sectores de la economía. De hecho, los beneficios tributarios y las minoraciones han sido empleadas constantemente como una forma de intervención del Estado en la economía con la finalidad de estimular determinadas actividades económicas (Forero, 2019, p. 23), en aras de jalonar el desarrollo de algunas industrias y, con ello, incentivar la creación de nuevas plazas de empleo.

$\mathrm{Al}$ respecto, la Corte Constitucional ha precisado que "las formas de intervención para fomento de la economía o de un sector de ella, pueden revestir diversas modalidades"; así, por ejemplo, señala que "el legislador puede estimular un sector económico mediante la política tributaria, adoptando exenciones, tasas o tarifas reducidas al sector económico que considera oportuno fomentar" (Corte Constitucional, Sentencia C-1108, 2001).

Asimismo, la Corte Constitucional ha acogido:

La distinción establecida por la doctrina fiscal entre beneficios tributarios y las así denominadas genéricamente minoraciones estructurales, según la cual estas últimas si bien reducen la carga impositiva o excluyen o exonera a un determinado sujeto del deber de contribuir representan simplemente un reconocimiento de los principios de tributación. (Corte Constitucional, Sentencia C-540, 2005).

Sin embargo, hay que ser conscientes de que cualquier beneficio tributario, reduciendo la carga de ciertos sectores de la economía con el propósito de fomentar determinadas industrias, conlleva a un elevado costo fiscal para las finanzas del Estado. Ya que el no recaudo tributario, producto de las exenciones o reducciones tributarias, implica menores ingresos para las arcas del Estado, disminuyendo con ello sus posibilidades de gasto e inversión social o viéndose 
obligado a aumentar el recaudo en otros ámbitos con una mayor tarifa o con una ampliación de gravámenes a efectos de compensar las concesiones dadas a los contribuyentes que gozan de dichos beneficios, tal como sucede con la recurrencia a ampliar los impuestos indirectos.

A lo anterior, se debe sumar el hecho de que el Estado a menudo no controla, ni ejerce una verdadera labor de supervisión y medición para evaluar si los beneficios, así como las minoraciones, efectivamente logran su cometido. En este contexto, algunos resaltan que "los beneficios tributarios deben contar con una correspondencia clara y precisa respecto de las medidas de los incentivos y los objetivos que se planea alcanzar, respaldados con una labor continua de seguimiento y evaluación" (Sarmiento, 2013, p. 300). Por esta razón, algunos apuntan al desmonte de dichos beneficios sectorizados (Plazas, 2019), incluso documentando empíricamente cómo en el ámbito nacional "la baja en los impuestos a las empresas no ha resultado ser definitiva en la lucha contra la informalidad y para la generación de empleo formal” (Farné, 2020, p. 20).

\section{Conclusiones}

Si bien la Corte ha sido acuciosa en su labor como máxima intérprete y guardiana de la supremacía e integridad constitucional, en el campo de conocimiento de las demandas de inconstitucionalidad dirigidas contra diferentes disposiciones tributarias y reformas al régimen jurídico en materia fiscal, el alto tribunal de lo constitucional ha sido muy respetuoso de la libertad de configuración que tiene el legislador tributario. En ese sentido, desde sus inicios ha fijado una estructura argumentativa orientada a ajustar el alcance de estos principios constitucionales a un Estatuto Tributario que venía de tiempo atrás y atendiendo de manera articulada, con poca intervención y mucho respeto, a las reformas tributarias que han promovido los diferentes gobiernos.

En pocas oportunidades se ha visto una interpretación constitucional activa, como en otros asuntos, a efectos de empoderar los principios de equidad y progresividad como suelen comprenderlos la doctrina y los demandantes de las normas tributarias. Así, por ejemplo, se resalta la articulación que ha hecho del mínimo vital a la capacidad diferenciada de contribuir, permitiendo con ello sustentar un límite a la imposición de gravámenes indirectos a productos básicos y esenciales de la canasta familiar.

Sin embargo, la misma tesis desarrollada por la Corte Constitucional de que los principios constitucionales deben ser valorados conjuntamente frente al sistema tributario y no respecto a cada impuesto en particular, especialmente con relación a los impuestos indirectos, ha promovido propuestas gubernamentales y legislativas que ingenian mecanismos de ampliación y afectación de la tarifa de productos de la canasta familiar a través de estrategias dirigidas a reflejar una progresión amplia predicable de políticas de reinversión del gasto social a los más pobres. En este contexto, se destaca la ampliación impositiva justificada con instrumentos como la devolución del IVA para los más pobres o la institucionalización de días sin IVA. 
A partir del contraste formulado entre el incremento de impuestos indirectos y la reducción de ciertos impuestos directos, pareciere, en términos generales, que la progresión tributaria significara la ampliación progresiva de impuestos indirectos y generalizados, mientras se progresa en desarrollo económico de ciertos sectores a través de exenciones y minoraciones que, por supuesto, pasan a ser solventadas por medio de la redistribución impositiva a todos. Independientemente del valor académico y jurídico que tiene la jurisprudencia constitucional en materia tributaria, estas tendencias cada vez más acentuadas de quienes dirigen la política fiscal y tributaria evidencian la necesidad de reconsiderar en el plano material y real los postulados fundamentales de la tributación que se han fijado desde 1991.

En ese sentido, recientemente se propuso una demanda de inconstitucionalidad que no se dirigía contra disposiciones específicas del Estatuto Tributario o contra una reforma tributaria en concreto, sino que se acusaba a todo el sistema tributario emanado de esta codificación de contrariar los fundamentos constitucionales de la progresividad y los otros principios fijados por el constituyente de 1991. En ejercicio de esta acción pública de inconstitucionalidad se solicitó a la Corte declarar la inexequibilidad del Decreto 624 de 1989 y que, a partir de una sentencia apelativa, pasara a diferir temporalmente sus efectos para que el Congreso de la República procediera a expedir una nueva codificación tributaria que cumpla materialmente con los principios de progresividad, equidad y eficiencia (Newman, Uprimny, Garay, Espitia, Ramírez, \& Jiménez, 2020, p. 44).

Sin embargo, la Corte inadmitió la demanda señalando, entre otras cosas, que las "pretensiones de la demanda exceden el ámbito de las competencias de la Corte”, pues a través de un exhorto se buscaba imponer un mandato al Congreso para la expedición de:

Un nuevo estatuto tributario, en un horizonte temporal limitado y con la supervisión y asesoramiento de una instancia de expertos, dispuesta por la Corte para una vigencia de 10 años, y con el seguimiento que se reservaría la Corte sobre la actividad del Congreso. (Corte Constitucional, Auto de 21 de julio de 2020, Exp. D-13762).

Con la inadmisión de esta demanda se elude, por lo menos de momento, la resolución de esta controversia jurídica planteada en el ámbito del sistema tributario, la cual busca reivindicar los propósitos axiológicos del Estado social de derecho a partir de lo decidido por la Asamblea Nacional Constituyente en 1991. 


\section{Referencias}

Auto del 21 de julio de 2020, expediente D-13762. Corte Constitucional de Colombia. Magistrado Sustanciador: Luis Guillermo Guerrero Pérez.

Avellaneda Bautista, C. A. (1997). La ciencia tributaria. Bogotá, Colombia: Multiletras Editores.

Bolaños Bolaños, L. (2017). Justicia tributaria como principio constitucional en el Estado social de derecho. Revista de Derecho, (48), 54-81. Recuperado de https://rcientificas.uninorte.edu.co/index.php/ derecho/article/view/8374

Buitrago Mora, J. S., \& Uribe Escobar, C. (2017). Análisis comparativo de los principios de equidad, eficiencia y progresividad tributaria en la composición y recaudo del impuesto al valor agregado en Colombia y Chile. Contexto, 6, 93-100. Recuperado de https://revistas.ugca.edu.co/index.php/ contexto/article/view/803

Cadavid Arango, L. A. (2014). Fundamentos de derecho comercial, tributario y contable 4. ${ }^{\text {a }}$ (ed.). Bogotá, Colombia: Ediciones Mc Graw Will.

Colombia. Constitución Política de Colombia (1991). Recuperada de http://www.secretariasenado.gov.co/ senado/basedoc/constitucion_politica_1991.html

Colombia. Decreto 3328 de 1963. Por el cual se establece el Impuesto sobre las Ventas. Recuperado de http://www.suin-juriscol.gov.co/viewDocument.asp?id=1819854

Colombia. Decreto 624 de 1989. Estatuto Tributario. Recuperado de http://www.secretariasenado.gov.co/ senado/basedoc/estatuto_tributario.html

Colombia. Decreto 2331 de 1998. Por el cual se dictan medidas tendientes a resolver la situación de los sectores financiero y cooperativo. Recuperado de http://www.suin-juriscol.gov.co/viewDocument. asp?id $=1437283$

Colombia. Ley 599 de 2000. Código Penal. Recuperada de http://www.secretariasenado.gov.co/senado/ basedoc/ley_0599_2000.html

Farné, S. (2020). ¿Menos impuestos a las empresas, más empleo formal? El caso de Colombia. Revista Instituto Colombiano de Derecho Tributario, 57(83), 1-23.

Ferré Olivé, J. C. (2014). El bien jurídico protegido en los delitos tributarios. Revista Justiça e Sistema Criminal, 6 (11), 7-42. Recuperado de https://revistajusticaesistemacriminal.fae.edu/direito/article/ view/28

Forero Hernández, C. F. (2019). El derecho tributario, ¿derecho administrativo o derecho económico? Dos mil tres mil, 21, 7-33. https://doi.org/10.35707/dostresmil/2101

Hincapié Gómez, M. (2014). Los principios rectores del derecho tributario. Nuevo Derecho, 10(15), 4754. Recuperado http://revistas.iue.edu.co/revistasiue/index.php/nuevoderecho/article/view/648

Newman Pont, E., Uprimny Yepes, R., Garay Salamanca, L. J., Espitia Zamora, J. E., Ramírez Gómez, C. E., \& Jiménez Ospina, A. (2020). Acción pública de inconstitucionalidad contra la integralidad del Decreto 624 de 1989, por el cual se expide el Estatuto Tributario, y las normas que lo modifican. Bogotá, Colombia: Dejusticia. Recuperado de https://www.dejusticia.org/wp-content/uploads/2020/05/ Demanda-Estatuto-Tributario-Dejusticia-2020.pdf 
Parra Dussan, C. (2012). El derecho a la igualdad en nuestro estado social. Bogotá, Colombia: Universidad Sergio Arboleda.

Plazas Vega, M. A. (2005). Derecho de la Hacienda Pública y derecho tributario. Bogotá, Colombia: Temis.

Plazas Vega, M. A. (2019). La ley de financiamiento desde una visión de hacienda pública y derecho tributario. Bogotá, Colombia: Temis.

Restrepo, J. C. (2012). La Hacienda Pública. Bogotá, Colombia: Universidad Externado de Colombia.

Romero Molina, C. A., Bernal Sánchez, L. V., \& Soto Contreras, E. (2012). El concepto de tributo en la jurisprudencia de la Corte Constitucional de Colombia. Dixi, 14(15), 118-131. Recuperado de https:// revistas.ucc.edu.co/index.php/di/article/view/1017

Romero Molina, C. A., Grass Suárez, Y. C., \& García Caicedo, X. C. (2013). Principios constitucionales que rigen el sistema tributario. Dixi, 15(17), 67-77. https://doi.org/10.16925/di.v15i17.640

Sarmiento Pérez, P. E. (2013). Beneficios tributarios del impuesto sobre la renta en Colombia. En El impuesto sobre la renta y complementarios. Consideraciones teóricas y prácticas (3. ${ }^{a}$ ed.) (pp. 273-303). Bogotá, Colombia: Universidad Externado de Colombia.

Sentencia C-094 de 1993. Corte Constitucional de Colombia. Magistrado Ponente: José Gregorio Hernández Galindo.

Sentencia C-228 de 1993. Corte Constitucional de Colombia. Magistrado Ponente: Vladimiro Naranjo Mesa.

Sentencia C-333 de 1993. Corte Constitucional de Colombia. Magistrado Ponente: Eduardo Cifuentes Muñoz.

Sentencia C-364 de 1993. Corte Constitucional de Colombia. Magistrado Ponente: Carlos Gaviria Díaz.

Sentencia C-556 de 1993. Corte Constitucional de Colombia. Magistrado Ponente: Jorge Arango Mejía.

Sentencia C-335 de 1994. Corte Constitucional de Colombia. Magistrado Ponente: José Gregorio Hernández Galindo.

Sentencia C-419 de 1995. Corte Constitucional de Colombia. Magistrado Ponente: Antonio Barrera Carbonell.

Sentencia C-183 de 1998. Corte Constitucional de Colombia. Magistrado Ponente: Eduardo Cifuentes Muñoz.

Sentencia C-597 de 2000. Corte Constitucional de Colombia. Magistrado Ponente: Álvaro Tafur Galvis.

Sentencia C-637 de 2000. Corte Constitucional de Colombia. Magistrado Ponente: Álvaro Tafur Galvis.

Sentencia C-1064 de 2001. Corte Constitucional de Colombia. Magistrados Ponentes: Manuel José Cepeda Espinosa y Jaime Córdoba Triviño.

Sentencia C-1107 de 2001. Corte Constitucional de Colombia. Magistrado Ponente: Jaime Araújo Rentería.

Sentencia C-1108 de 2001. Corte Constitucional de Colombia. Magistrados Ponentes: Rodrigo Escobar Gil y Marco Gerardo Monroy Cabra.

Sentencia C-711 de 2001. Corte Constitucional de Colombia. Magistrado Ponente: Jaime Araújo Rentería. 
Sentencia C-734 de 2002. Corte Constitucional de Colombia. Magistrado Ponente: Manuel José Cepeda Espinosa.

Sentencia C-261 de 2002. Corte Constitucional de Colombia. Magistrada Ponente: Clara Inés Vargas Hernández.

Sentencia C-776 de 2003. Corte Constitucional de Colombia. Magistrado Ponente: Manuel José Cepeda Espinosa.

Sentencia C-989 de 2004. Corte Constitucional de Colombia. Magistrado Ponente: Clara Inés Vargas Hernández.

Sentencia C-540 de 2005. Corte Constitucional de Colombia. Magistrado Ponente: Humberto Antonio Sierra Porto.

Sentencia C-704 de 2010. Corte Constitucional de Colombia. Magistrada Ponente: María Victoria Calle Correa.

Sentencia C-397 de 2011. Corte Constitucional de Colombia. Magistrado Ponente: Jorge Ignacio Pretelt Chaljub.

Sentencia C-891 de 2012. Corte Constitucional de Colombia. Magistrado Ponente: Jorge Ignacio Pretelt Chaljub.

Sentencia C-291 de 2015. Corte Constitucional de Colombia. Magistrado Ponente: Gloria Stella Ortiz Delgado.

Upegui Mejía, J. C. (2011). Principios constitucionales del derecho tributario en Colombia y México. Revista de Derecho Fiscal, (5), 131-161. Recuperado de https://revistas.uexternado.edu.co/index.php/ fiscal/article/view/2747 